\title{
Transgenic Models to Study Diseases of the.Nervous System: An In Vivo Approach to Dissect Complex Pathogenetic Networks
}

\author{
L. Mucke
}

\section{Introduction}

Diseases of the nervous system often pose particular challenges, both in terms of their pathogenetic complexity and their refractoriness to conventional therapeutic strategies. Multiple sclerosis, Alzheimer's disease (AD), and the human immunodeficiency virus 1 (HIV-1) associated cognitive/motor complex dramatically illustrate this point. Because many disease processes that afflict the central nervous system (CNS) evolve slowly, the neuropathologist is often confronted with postmortem material that reflects the intricate combination of causative and compensatory processes. Unfortunately, many features of CNS diseases are also difficult to dissect with in vitro models because of the extensive interactions between different types of predominantly nondividing cells that characterize the adult CNS. Nevertheless, both in vitro models and the pathologic analysis of nervous tissue have provided important leads as to which cellular activities, gene products, infectious agents, or chemical compounds may constitute potential etiologic factors in the development of neurologic illnesses. The association of increased/aberrant expression of major histocompatibility complex (MHC) antigens with autoimmune diseases (for reviews see Bottazzo et al. 1983, 1986; Janeway et al. 1984); of amyloid $\beta$ protein and $\alpha_{1}$-antichymotrypsin (ACT) with AD (for reviews see Selkoe 1991a, b), and of HIV-1 envelope proteins with acquired immundeficiency syndrome (AIDS) dementia (reviewed by Lipton 1992) represent important examples. For the rational design of therapeutic strategies it is, however, often desirable to prove that a suspected pathogenetic factor is sufficient to cause specific disease manifestations in vivo or to define the exact role a protein plays in a multifactorial pathogenetic cascade. This is illustrated, for example, by the disappointing effects that different cytokines had on the course of multiple sclerosis when they were used as therapeutic agents in clinical trials (Knobler et al. 1984; Camenga et al. 1986; Johnson 1988). However, the in vivo analysis and experimental/therapeutic manipulation of cells and chemical factors within the brain parenchyma is complicated by the blood-brain barrier. Direct injections of pathogenetic factors into the parenchyma of the CNS are also problematic. The associated trauma induces a large number of vigorous secondary responses, and the focal concentration of the injected proteins may vary substantially from injection to injection. 
Fusion gene constructs expressed in transgenic animals allow the delivery of selected protein factors to specific areas/cells within the intact organism and hence can overcome some of the obstacles outlined above. This chapter provides an outline of how transgenic models may help advance the in vivo analysis of major neurologic diseases.

\section{Expression of Proteins in the CNS of Transgenic Mice}

Many excellent reviews have been published on the production and use of transgenic animals (Hogan et al. 1986; Brinster and Palmiter 1986; Gordon 1986; Palmiter and Brinster 1986; Arnold and Hämmerling 1991; Merlino 1991). Mice expressing prion genes (for review see Prusiner 1991) or DNAs encoding the human poliovirus receptor (Ren et al. 1990; Ren and Racaniello 1992) have demonstrated the enormous potential of transgenic models in the analysis of neurologic diseases. The subsequent section summarizes some basic aspects of transgenic technology and points out certain caveats that should be kept in mind when considering this experimental approach.

\section{Basic Principles of Transgenic Technology}

Typically, between one and 100 transgene molecules encoding a protein of interest integrate into a random site within the genome when injected into a fertilized egg cell. The integration site of the transgene within the chromatin can dramatically influence its expression (reviewed by Wilson 1990). Because of the randomness of the integration event, transgenic mice that develop from different microinjected zygotes (founders) can show marked differences in the levels and patterns of transgene expression and hence also in their phenotype. Consequently, lines of transgenic mice carrying the same transgene but derived from separate founders may also differ substantially from each other at the expression level. Most founders transmit the transgene to approximately $50 \%$ of their offspring when mated with normal nontransgenic mice. Transgenic mice derived from the same founder usually show very similar levels and patterns of transgene expression.

While the introduction of transgenes into the murine genome has now become a routine procedure in many laboratories, the experimental regulation of the transgene expression continues to be one of the more challenging aspects of transgenic technology. Many features of the fusion gene and of the chromatin surrounding its integration site influence the areas within the body where the transgene encoded protein is expressed, the cell type which produces it, the kinetics of its expression during development, as well as the overall amount and focal concentration of the transgene product (Swain et al. 1987; Brinster et al. 1988; Bonifer et al. 1990; Wilson 1990; Choi et al. 1991; Palmiter et al. 1991). It should also be noted in this context that the expression of fusion genes in cultured cells unfortunately does not reliably 
predict their expression in vivo (Palmiter et al. 1991, and our own unpublished observations).

\section{Targeting the Expression of Fusion Genes to Specific Cell Types Within the CNS}

In the majority of CNS diseases clinical signs and symptoms are related most directly to an impairment of neuronal functions. However, increasing evidence suggests that nonneuronal CNS cells can act as important mediators of neurologic disease processes. Because astrocytes are widely distributed throughout the CNS and participate in diverse biologic processes, including neural-immune interactions (Kimelberg and Norenberg 1989; Frohman et al. 1989; Lieberman et al. 1989), they form excellent targets for the in vivo expression of a number of interesting molecules. Hence, we developed a DNA construct that allows the astrocyte-specific expression of hybrid genes in transgenic mice (Mucke et al. 1991). The regulatory sequences that direct the expression of transgenes in this construct were adopted from the glial fibrillary acidic protein (GFAP) gene. The GFAP gene encodes a relatively abundant intermediate filament cytoskeletal protein (Lewis et al. 1984); Balcarek and Cowan 1985) that is restricted primarily to astroglia (Bignami et al. 1972). Interestingly, the expression of the GFAP gene is upmodulated dramatically by diverse forms of neural injury (Bignami and Dahl 1976; Smith et al. 1983; De La Monte et al. 1987; Delacourte 1990).

A GFAP-lacZ fusion gene was constructed (Mucke et al. 1991) by replacing a 50-bp fragment of the first exon of the GFAP gene with the Escherichia coli lac $Z$ reporter gene. The lac $Z$ gene encodes bacterial beta-galactosidase ( $\beta$-gal) which can be detected readily in tissue sections by the formation of a blue precipitate upon staining with X-gal (An et al. 1982; Hall et al. 1983; Sanes et al. 1986). The GFAP-lac $Z$ fusion gene effectively monitors astrocyte activity in vivo, facilitates the analysis of early astroglial activation events, and demonstrates the characteristic expression pattern directed by our GFAP construct. Germline injection of the GFAP-lac $Z$ construct resulted in six separate lines of transgenic mice. In all six lines, the expression of $\beta$-gal was restricted to astrocytes. In unmanipulated transgenics, $\beta$-gal activity was much more prominent in astrocytes of the hippocampal formation, selected white matter tracts, and glial limitans than in astrocytes of other areas. This expression pattern illustrates the physiologic heterogeneity of astrocytes and likely reflects differences in functional demands placed on these cells in different brain regions. Because astroglial activation is accompanied by an increased expression of the GFAP gene, the expression of the GFAP-lacZ fusion gene could be upmodulated experimentally with gliosis-provoking maneuvers such as focal mechanical trauma (Fig. 1). In two lines of GFAP-lac $Z$ transgenic mice no $\beta$-gal expression was seen in the unmanipulated state, but transgene expression was inducible by focal injury. The ability to focally upmodulate the expression of transgenes at defined time points in 

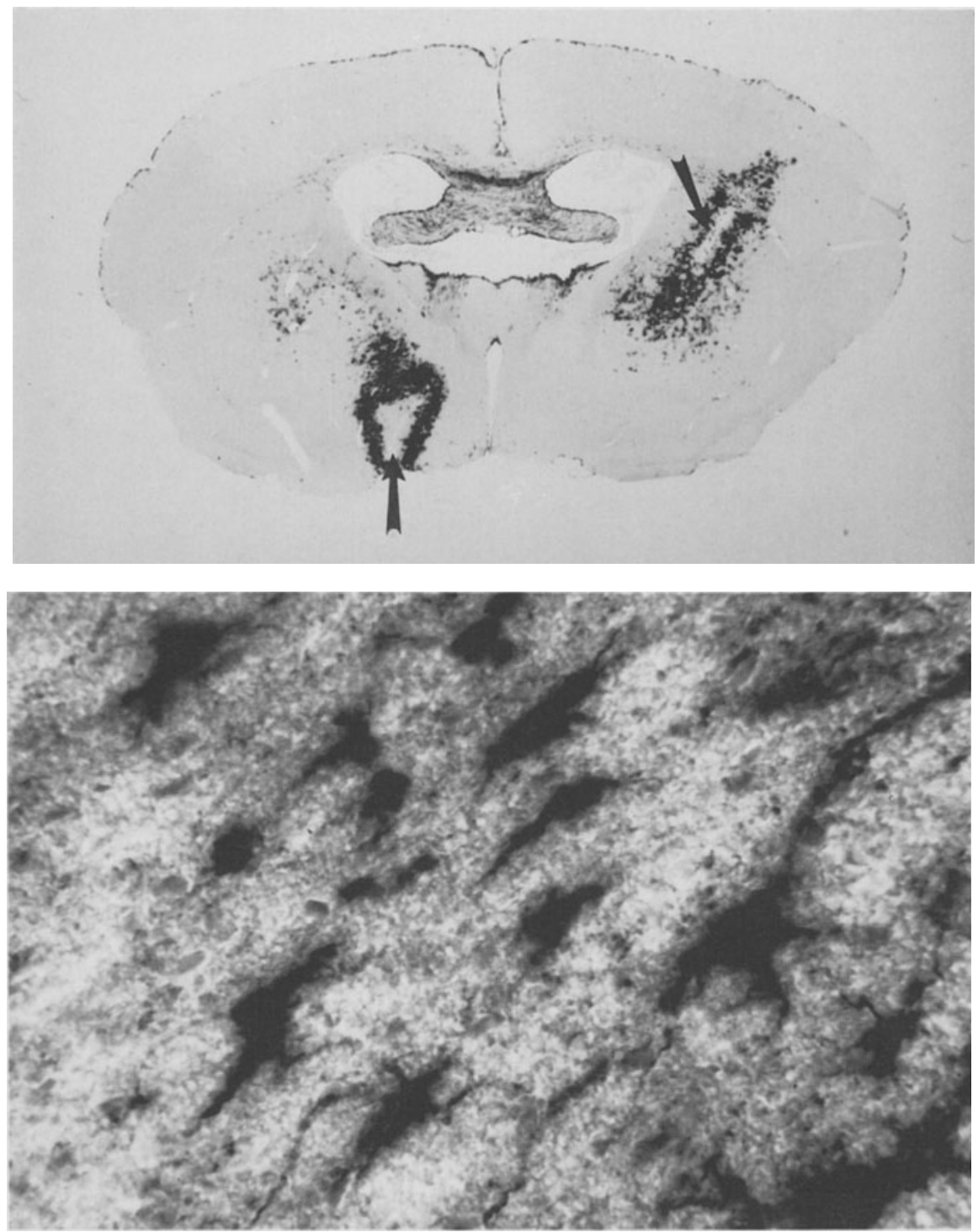

Fig. 1. Hybrid gene expression directed by the GFAP construct. The pattern of hybrid gene expression directed by the modified GFAP gene is revealed in mice transgenic for a GFAP-lac $Z$ fusion gene by staining with X-gal (dark precipitate indicates $\beta$-gal activity). While in unmanipulated mice hybrid gene expression was seen primarily in the hippocampal formation, major white matter tracts and along the glial limitans, transgene expression could be effectively upmodulated in all brain regions by focal injury. Upper panel, frontal brain section $(\times 10$; stained with X-gal and eosion) of a GFAP-lac $Z$ transgenic mouse showing intense induction of $\beta$-gal expression by reactive astrocytes around two foci of mechanically induced tissue necrosis (arrows). Lower Panel, astrocytes in the fimbria hippocampi of an unmanipulated GFAP-lacZ transgenic mouse $(\times 190$; stained with X-gal and hematoxylin) 
the adult CNS by activation of astrocytes represents a major advantage of the GFAP vector because it allows experimental manipulation of the levels of transgene products in different brain regions of the same animal. In transgenic mice with low baseline expression it also makes it possible to assess detrimental proteins that would be lethal if expressed constitutively at higher levels.

The GFAP vector has already been used successfully to express a variety of biologically active molecules such as MHC antigens, viral products, cytokines and enzymes in astrocytes of transgenic mice (see examples below). These studies are expected to provide insights into the pathogenesis of viral - and immune-mediated neurologic diseases as well as neurodegenerative disorders.

\section{Transgenic Models}

Many neurologic disease processes are mediated by proteins derived either from the host (e.g., cytokines and amyloid $\beta$ protein) or from the environment (e.g., microbial products). While rodent models can probably never faithfully simulate all aspects of a human disease, the expression of potentially pathogenetic factors in the CNS of transgenic mice should

a) help decide whether these factors are sufficient to induce certain disease manifestations or require cofactors,

b) provide valuable general information on their effects within the intact adult CNS,

c) allow the study of interactions between different factors in vivo by crossing lines of transgenic mice that express individual proteins, and

d) facilitate the development of novel therapeutic strategies based on the experimental manipulation of proteins with confirmed pathogenetic activity.

\section{Presentation of Viral Antigens by Transgenic Astrocytes Expressing an MHC Class I Minigene}

Abnormal immune responses feature prominently in the pathogenesis of a number of neurologic diseases. Multiple sclerosis, acute disseminated encephalomyelitis and experimental allergic encephalomyelitis are examples of such disorders with a predeliction for the CNS. While the CNS used to be considered an immunologically privileged site, more recent studies have shown that activated $\mathrm{T}$ lymphocytes can traverse the blood-brain barrier and migrate through the brain parenchyma (Wekerle et al. 1986, 1987; Hickey et al. 1991). An important prerequisite for the efficient presentation of antigens to Tcells is the expression of MHC antigens (Doherty and Zinkernagel 1974; Zinkernagel and Doherty 1974, 1983; Janeway et al. 1984). It has been hypothesized that increased/aberrant MHC expression can intensify immune 
surveillance and may even be a critical pathogenetic factor in the development of a number of autoimmune diseases (Bottazzo et al. 1983, 1986; Wekerle et al. 1986). While there is little evidence for MHC expression on brain cells in the normal state, a number of factors can upmodulate MHC expression in astrocytes (Wong et al. 1984; Hickey et al. 1985; Massa and ter Meulen 1987; Massa et al. 1987; Suzumura et al. 1986, 1988). Because these findings suggest that antigen presentation within the CNS could be involved in the pathogenesis of immune-mediated neurologic diseases we chose (in collaboration with G. Rall, M. Nerenberg, and M. Oldstone) to assess and manipulate the antigenpresenting capacity of astrocytes in vitro and in vivo.

A minigene encoding the MHC class $I$ antigen $D^{b}$ was expressed in astrocytes of transgenic $\mathrm{C} 57 \mathrm{BL} / 6\left(\mathrm{H}-2^{\mathrm{b}}\right)$ and $\mathrm{BALB} / \mathrm{c}\left(\mathrm{H}-2^{\mathrm{d}}\right)$ mice with the help of the GFAP vector (see above). The astroglial expression of a functional MHC class I glycoprotein derived from the GFAP-D ${ }^{\mathrm{b}}$ fusion gene and the antigen-presenting capacity of GFAP-D ${ }^{b}$ transgenic astrocytes were demonstrated in chromium release assays. Primary astrocytes obtained from transgenic $\mathrm{BALB} / \mathrm{c}$ mice $\left(\mathrm{H}-2^{\mathrm{d}}\right)$ expressing the allogeneic $\mathrm{D}^{\mathrm{b}}$ molecule were able to present lymphocytic choriomeningitis virus (LCMV) antigens to $\mathrm{D}^{\mathrm{b}}$-restricted, LCMV-primed cytotoxic $\mathrm{T}$ cells whereas astrocytes from nontransgenic $\mathrm{BALB} / \mathrm{c}$ mice $\left(\mathrm{D}^{\mathrm{b}}\right.$ negative) were not. Our data are in agreement with previous reports on the antigen-presenting capacity of astrocytes (Fontana et al. 1984, 1986; Fierz et al. 1985; Male et al. 1987; Skias et al. 1987). Other studies have demonstrated the importance of microglia as antigen-presenting cells in the CNS (Giulian 1987; Lassmann et al. 1991). The proficient antigen presentation by microglia makes the assessment of antigen presentation by astrocytes in explant cultures problematic because such cultures can easily become contaminated with microglia despite vigorous selection methods. However, our GFAP-D ${ }^{\mathrm{b}}$ transgenic BALB/c $\left(\mathrm{H}-2^{\mathrm{d}}\right)$ mice circumvent this problem because antigen presentation by $\mathrm{BALB} / \mathrm{c}$ microglia would be $\mathrm{H}-2^{\mathrm{d}}$ restricted and could not have contributed directly to the $\mathrm{D}^{\mathrm{b}}$ restricted presentation of LCMV antigens in our cultures of GFAP-D ${ }^{b}$ transgenic $\mathrm{BALB} / \mathrm{c}$ astrocytes.

The GFAP-D ${ }^{b}$ transgenic model combines inducibility of transgene expression by focal neurologic injury, mediated through the regulatory sequences adopted from the GFAP gene (see above), with the capacity of transgenic astrocytes to present viral antigens to immune cells. Hence, the model should allow us to assess the combination of aberrant MHC expression and environmental insults, an interaction of potential importance in the pathogenesis of autoimmune diseases.

\section{Transgenic Models to Study the Neurologic Manifestations of Alzheimer's Disease (AD) and HIV-1-Infection}

The dementia of AD is accompanied by the cerebral accumulation of abnormal proteins derived from the amyloid $\beta$ protein precursor (APP). 
Increasing evidence suggests that these proteins are detrimental to the surrounding brain cells and may be a major cause of the symptoms seen in AD (for reviews see Selkoe 1991a, b; Yankner and Mesulam 1991). The close association of three different APP point mutations (affecting the same amino acid in the transmembrane domain of the molecule) with early-onset familial AD (Chartier-Harlin et al. 1991; Goate et al. 1991; Murrell et al. 1991) substantiate the suspicion that APP is causally involved in AD.

To test their pathogenetic potential in vivo, mutated and nonmutated forms of human APP were expressed in brains of transgenic mice (in collaboration with S. Forss-Petter and C. Abraham). For expression in neurons, cDNAs encoding full-length human APPs were fused with a vector derived from the neuron-specific enolase (NSE) gene. Four different NSE-APP fusion genes were constructed encoding different forms of either wild-type/nonmutated APP or APP carrying the Val $\rightarrow$ Ile change found in cases of familial AD (Goate et al. 1991). Fusion genes were injected individually into the germline of mice. Expression of the four NSE-APP constructs was detectable by standard northern and western analysis. Neuronal expression of human APPs was demonstrated by immunostaining of brain sections (fixed in $70 \%$ ethanol/ $0.15 \mathrm{M} \mathrm{NaCl}$ ) with an anti-human APP antibody $(\alpha C 5)$ from Athena Neurosciences (San Francisco, CA). For each NSE-APP construct, two to five lines of transgenic mice with clearcut cerebral expression of human APPs were analyzed. Our transgenic models make it possible to quantitate differences in the effects of mutated and nonmutated forms of human APP in vivo.

Within the neuritic plaques of $\mathrm{AD}$, amyloid $\beta$ protein is closely associated with the serine protease inhibitor ACT (Abraham et al. 1988). It is possible that ACT interacts with a region in the $\beta$ protein which resembles the active site of a serine protease (C. Abraham, personal communication). ACT could also be indirectly involved in the abnormal proteolytic degradation of APP, by means of inhibiting one or more of the proteases that normally digest it. To assess whether the overproduction of $\mathrm{ACT}$ found in $\mathrm{AD}$ brains represents a beneficial compensatory response or a detrimental pathogenetic factor, a cDNA-encoding human ACT was fused with the GFAP vector. Six separate lines of GFAP-ACT transgenic mice were established. Expression of human ACT mRNA and protein were demonstrated in the brains of GFAP-ACT transgenic mice by northern and western analyses. To assess the interaction of ACT with APP in vivo, APP/ACT doubly transgenic mice are currently being produced by crossing lines of NSE-APP with GFAP-ACT transgenic mice.

Another devastating dementia that has emerged only recently but is rapidly becoming of major importance is associated with HIV-1 infection (Navia et al. 1986; Navia and Price 1987; Price and Brew 1988). In vitro evidence suggests that the HIV-1 envelope glycoprotein gp120 may be directly or indirectly responsible for the neuronal dysfunction that underlies AIDS dementia (Brenneman et al. 1988; Giulian et al. 1990; Lipton et al. 1991; Lipton 1992). To assess the pathogenetic potential of HIV-1 gp120 in vivo we have produced transgenic mice with either neuronal or astroglial 
expression of the HIV-1 gp120 molecule. Transgenic models were also established (in collaboration with I. Campbell) to determine the potential contribution of different cytokines to the development of neurologic dysfunction.

It is our hope that the analysis of the transgenic models described above will lead to the identification of novel therapeutic strategies for the treatment and prevention of the neurologic impairment seen in AD and HIV-1 infection.

\section{An Approach to Multifactorial Etiologies}

As outlined above, the effects of individual proteins can be assessed in vivo by expressing them in specific cells of transgenic mice. When targeted to the CNS, some factors (e.g. interleukin-6) are sufficient to induce specific neuropathologic and clinical disease manifestations (see Campbell et al. 1992). Other proteins, however, may participate in complex multifactorial pathogenetic networks and require one or more cofactors for the induction of disease. At this point in time; it seems likely that the involvement of amyloid proteins in $\mathrm{AD}$ and of $\mathrm{MHC}$ molecules in multiple sclerosis will turn out to be examples of such complex scenarios. It is to be hoped that the experimental manipulation of transgenic mice expressing combinations of different fusion genes (see, for example, the NSE-APP/GFAP-ACT doubly transgenic mice above) will facilitate the in vivo analysis of neurologic diseases with multifactorial etiologies.

Acknowledgments. We thank W. Johnson, E. Rockenstein, and J. Price for excellent technical support and G. Rall for helpful comments on the manuscript. This research was supported by the Harry Weaver Neuroscience Scholar Award from the National Multiple Sclerosis Society, Faculty Scholar Award from the Alzheimer's Association, and NIH grant AG-04342.

\section{References}

Abraham CR, Selkoe DJ, Potter H (1988) Immunochemical identification of the serine protease inhibitor alpha1-antichymotrypsin in the brain amyloid deposits of Alzheimer's disease. Cell 52:487-501

An G, Hidaka K, Siminovitch L (1982) Expression of bacterial beta-galatosidase in animal cells. Mol Cell Biol 2:1628-1632

Arnold B, Hämmerling GJ (1991) MHC class-I transgenic mice. Annu Rev Immunol 9:297-322

Balcarek JM, Cowan NJ (1985) Structure of the mouse glial fibrillary acidic protein gene: implications for the evolution of the intermediate filament multigene family. Nucleic Acids Res 13:5527-5543

Bignami A, Dahl D (1976) The astroglial response to stabbing. Immunofluorescence studies with antibodies to astrocyte-specific protein (GFA) in mammalian and submammalian vertebrates. Neuropathol Appl Neurobiol 2:99-110

Bignami A, Eng LF, Dahl D, Uyeda CT (1972) Localization of glial fibrillary acidic protein in astrocytes by immunofluorescence. Brain Res 43:429-435 
Bonifer C,Vidal M, Grosveld F, Sippel AE (1990) Tissue specific and position independent expression of the complete gene domain for chicken lysozyme in transgenic mice. EMBO J 9:2843-2848

Bottazzo GF, Pujol-Borrell R, Hanafusa T, Feldmann M (1983) Role of aberrant HLA-DR expression and antigen presentation in induction of endocrine autoimmunity. Lancet 2:1115-1119

Bottazzo GF, Todd I, Mirakian R, Belfiore A, Pujol-Borrell R (1986) Organ-specific autoimmunity: a 1986 overview. Immunol Rev 94:137-169

Brenneman DE, Westbrook GL, Fitzgerald SP, Ennist DL, Elkins KL, Ruff MR, Pert CB (1988) Neuronal cell killing by the envelope protein of HIV and its prevention by vasoactive intestinal peptide. Nature 335:639-642

Brinster RL, Palmiter RD (1986) Introduction of genes into the germline of animals. Harvey Lectures Ser 80:1-38

Brinster RL, Allen JM, Behringer RR, Gelinas RE, Palmiter RD (1988) Introns increase transcriptional efficiency in transgenic mice. Proc Natl Acad Sci USA 85:836-840

Camenga DL, Johnson KP, Alter M, Engelhardt CD, Fishman PS, Greenstein JI, Haley AS, Hirsch RL, Kleiner JE, Kofie VY, et al (1986) Systemic recombinant alpha-2 interferon therapy in relapsing multiple sclerosis. Arch Neurol 43:1239-1246

Campbell IL, Oldstone MBA, Mucke L (1992) Neurologic disease induced in transgenic mice by the astrocyte-specific expression of interleukin-6. Soc Neurosci Abstr (in press)

Chartier-Harlin M-C, Crawford F, Houlden H, Warren A, Hughes D, Fidani L, Goate A, Rossor M, Roques P, Hardy J, Mullan M (1991) Early-onset Alzheimer's disease caused by mutations at codon 717 of the beta-amyloid precursor protein gene. Nature 353:844-846

Choi T, Huang M, Gorman C, Jaenisch R (1991) A generic intron increases gene expression in transgenic mice. Mol Cell Biol 11:3070-3074

De La Monte SM, Ho DD, Schooley RT, Hirsch MS, Richardson EPJr (1987) Subacute encephalomyelitis of AIDS and its relation to HTLV-III infection. Neurology 37:562-569

Delacourte A (1990) General and dramatic glial reaction in Alzheimer brains. Neurology 40:33-37

Doherty PC, Zinkernagel RM (1974) T-cell-mediated immunopathology in viral infections. Transplant Rev 19:89-120

Fierz W, Endler B, Reske K, Wekerle H, Fontana A (1985) Astrocytes as antigen-presenting cells. I. Induction of Ia antigen expression on astrocytes by Tcells via immune interferon and its effect on antigen presentation. J Immunol 134:3785-3793

Fontana A, Fierz W, Wekerle H (1984) Astrocytes present myelin basic protein to encephalitogenic T-cell lines. Nature 307:273-276

Fontana A, Erb P, Pircher H, Zinkernagel R, Weber E, Fierz W (1986) Astrocytes as antigen-presenting cells. II. Unlike $\mathrm{H}-2 \mathrm{~K}$-dependent cytotoxic Tcells, $\mathrm{H}$-2Ia-restricted T cells are only stimulated in the presence of interferon gamma. J Neuroimmunol 12:15-28

Frohman EM, van den Noort S, Gupta S (1989) Astrocytes and intracerebral immune responses. J Clin Immunol 9:1-9

Giulian, D (1987) Ameboid microglia as effectors of inflammation in the central nervous system. J Neurosci Res 18:155-171

Giulian D, Vaca K, Noonan CA (1990) Secretion of neurotoxin by mononuclear phagocytes infected with HIV-1. Science 250:1593-1596

Goate A, Chartier-Harlin M-C, Mullan M, Brown J, Crawford F, Fidani L, Giuffra L, Haynes A, Irving N, James L, Mant R, Newton P, Rooke K, Roques P, Talbot C, Pericak-Vance M, Roses A, Williamson R, Rossor M, Owen M, Hardy J (1991) Segregation of a missense mutation in the amyloid precursor protein gene with familial Alzheimer's disease. Nature 349:704-706

Gordon JW (1986) Transgenic mice in immunology. M Sinai J Med 53:223-231 
Hall CV, Jacob PE, Ringold GM, Lee F (1983) Expression and regulation of Escherichia coli lacZ gene fusions in mammalian cells. J Mol Appl Genet 2:101-109

Hickey WF, Osborn JP, Kirby WM (1985) Expression of Ia molecules by astrocytes during acute experimental allergic encephalomyelitis in the Lewis rat. Cell Immunol 91:528-535

Hickey WF, Hsu BL, Kimura H (1991) T-lymphocyte entry into the central nervous system. J Neurosci Res 28:254-260

Hogan B, Costantini F, Lacy E (1986) Manipulating the mouse embryo. A laboratory manual. Cold Spring Harbor Laboratory, Cold Spring Harbor

Janeway CAJr, Bottomly K, Babich J, Conrad P, Conzen S, Jones B, Kaye J, Katz M, McVay L, Murphy DB, Tite J (1984) Quantitative variation in Ia antigen expression plays a central role in immune regulation. Immunol Today 5:99-105

Johnson KP (1988) Treatment of multiple sclerosis with various interferons: the cons Neurology 38:62-65

Kimelberg HK, Norenberg MD (1989) Astrocytes Sci Am 66-76

Knobler RL, Panitch HS, Braheny SL, Sipe JC, Rice GP, Huddlestone JR, Francis GS, Hooper CK, Kamin Lewis RM, Johnson KP, et al (1984) Systemic alpha-interferon therapy of multiple sclerosis. Neurology 34:1273-1279

Lassmann H, Zimprich F, Vass K, Hickey WF (1991) Microglial cells are a component of the perivascular glia limitans. J Neurosci Res 28:236-243

Lewis SA, Balcarek JM, Krek V, Shelanski M, Cowan NJ (1984) Sequence of a cDNA clone encoding mouse glial fibrillary acidic protein: structural conservation of intermediate filaments. Proc Natl Acad Sci USA 81:2743-2746

Lieberman AP, Ptha PM, Shin HS, Shin ML (1989) Production of tumor necrosis factor and other cytokines by astrocytes stimulated with lipopolysaccharide or a neurotropic virus. Proc Natl Acad Sci USA 86:6348-6352

Lipton SA (1992) Models of neuronal injury in AIDS: another role for the NMDA receptor? Trends Neurosci 15:75-79

Lipton SA, Sucher NJ, Kaiser PK, Dreyer EB (1991) Synergistic effects of HIV coat protein and NMDA receptor-mediated neurotoxicity. Neuron 7:111-118

Male DK, Pryce G, Hughes CC (1987) Antigen presentation in brain: MHC induction on brain endothelium and astrocytes compared. Immunology 60:453-459

Massa PT, ter Meulen V (1987) Analysis of Ia induction on Lewis rat astrocytes in vitro by virus particles and bacterial adjuvants. J Neuroimmunol 13:259-271

Massa PT, Brinkmann R, ter Meulen V (1987) Inducibility of Ia antigen on astrocytes by murine coronavirus JHM is rat strain dependent. J Exp Med 166:259-264

Merlino GT (1991) Transgenic animals in biomedical research. FASEB J 5:2996-3001

Mucke L, Oldstone MBA, Morris JC, Nerenberg MI (1991) Rapid activation of astrocyte-specific expression of GFAP-lacZ transgene by focal injury. New Biologist 3:465-474

Murrell J, Farlow M, Ghetti B, Benson MD (1991) A mutation in the amyloid precursor protein associated with hereditary Alzheimer's disease. Science 254:97-99

Navia BA, Price RW (1987) The acquired immunodeficiency syndrome dementia complex as the presenting or sole manifestation of human immunodeficiency virus infection. Arch Neurol 44:65-69

Navia BA, Cho ES, Petito CK, Price RW (1986) The AIDS dementia complex. II. Neuropathology Ann Neurol 19:525-535

Palmiter RD, Brinster RL (1986) Germ-line transformation of mice. Annu Rev Genet 20:465-499

Palmiter RD, Sandgren EP, Avarbock MR, Allen DD, Brinster RL (1991) Heterologous introns can enhance expression of transgenes in mice. Proc Natl Acad Sci USA 88:478-482

Price RW, Brew BJ (1988) The AIDS dementia complex. J Infect Dis 158: 1079-1083

Prusiner SB (1991) Molecular biology and transgenetics of prion diseases. Crit Rev Biochem Mol Biol 26:397-438 
Ren R, Racaniello VR (1992) Human poliovirus receptor gene expression and poliovirus tissue tropism in transgenic mice. J Virol 66:296-304

Ren RB, Costantini F, Gorgacz EJ, Lee JJ, RacanielloVR (1990) Transgenic mice expressing a human poliovirus receptor: a new model for poliomyelitis. Cell 63:353-362

Sanes JR, Rubenstein JLR, Nicolas J-F (1986) Use of a recombinant retrovirus to study post-implantation cell lineage in mouse embryos. EMBO J 5:3133-3142

Selkoe DJ (1991a) The molecular pathology of Alzheimer's disease. Neuron 6:487-496

Selkoe DJ (1991b) Amyloid protein in Alzheimer's disease. Sci Am 11:68-78

Skias DD, Kim D-K, Reder AT, Antel JP, Lancki DW, Fitch FW (1987) Susceptibility of astrocytes to class I MHC antigen-specific cytotoxicity. J Immunol 138:3254-3258

Smith ME, Somera FP, Eng LF (1983) Immunocytochemical staining for glial fibrillary acidic protein and the metabolism of cytoskeletal proteins in experimental allergic encephalomyelitis. Brain Res 264:241-253

Suzumura A, Lavi E, Weiss SR, Silberberg DH (1986) Coronavirus infection induces H-2 antigen expression on oligodendrocytes and astrocytes. Science 232:991-993

Suzumura A, Lavi E, Bhat S, Murasko D, Weiss SR, Silberberg DH (1988) Induction of glial cell MHC antigen expression in neurotropic coronavirus infections. Characterization of the $\mathrm{H}$-2-inducing soluble factor elaborated by infected brain cells. J Immunol 140:2068-2072

Swain JL, Stewart TA, Leder P (1987) Parental legacy determines methylation and expression of an autosomal transgene: a molecular mechanism for parental imprinting. Cell 50:719-727

Wekerle H, Linington C, Lassmann H, Meyermann R (1986) Cellular immune reactivity within the CNS. Trends Neurosci 9:271-277

Wekerle H, Sun D, Oropeza-Wekerle RL, Meyermann R (1987) Immune reactivity in the nervous system: modulation of T-lymphocyte activation by glial cells. J Exp Biol $132: 43-57$

Wilson C (1990) Position effects on eukaryotic gene expression. Annu Rev Cell Biol 6:679-714

Wong GH, Bartlett PF, Clark Lewis I, Battye F, Schrader JW (1984) Inducible expression of $\mathrm{H}-2$ and Ia antigens on brain cells. Nature 310:688-691

Working Group of the American Academy of Neurology AIDS Task Force (1991) Nomenclature and research case definitions for neurologic manifestations of human immunodeficiency virus-type 1 (HIV-1) infection. Neurology 41:778-785

Yankner BA, Mesulam M-M (1991) Beta-amyloid and the pathogenesis of Alzheimer's disease. N Engl J Med 325:1849-1857

Zinkernagel RM, Doherty PC (1974) Restriction of in vitro Tcell mediated cytotoxicity in lymphocytic choriomeningitis within a syngeneic or semiallogeneic system. Nature 248:701

Zinkernagel RM, Doherty PC (1983) MHC-restricted cytotoxic T cells: studies on the biological role of polymorphic major transplantation antigens determining $\mathrm{T}$ cell restriction-specificity, function, and responsiveness. Adv Immunol 27:51-77 